\title{
"How can a drug to treat claudication in adults save preterm newborns?"
}

\author{
Serife Kurul $^{1} \cdot$ Karel Allegaert $^{2,3} \cdot$ Robert B. Flint $^{1,3} \cdot$ H. Rob Taal ${ }^{1}$ \\ Published online: 16 March 2020 \\ (C) Springer-Verlag GmbH Germany, part of Springer Nature 2020
}

Keywords Neonatal $\cdot$ Sepsis $\cdot$ Pentoxifylline $\cdot$ Drug repurposing

\author{
Abbreviations \\ NEC Necrotizing enterocolitis \\ PTX Pentoxifylline \\ TNF-a Tumor necrosis factor alfa
}

\section{Introduction}

Pentoxifylline (Trental®) (PTX) is a vasoactive drug, registered in 1972 to treat intermittent claudication in adults. More recently, this drug has been of growing interest in different conditions such as renal, vascular, inflammatory, and infectious diseases. Particularly, it has been suggested that PTX could be beneficial for sepsis in preterm neonates. A recent Cochrane review including 6 relatively small studies showed that PTX improves survival in neonatal sepsis [1]. How can PTX, initially developed for a completely different population and indication, save premature newborns with sepsis?

Karel Allegaert

karel.allegaert@uzleuven.be

Serife Kurul

s.kurul@erasmusmc.nl

Robert B. Flint

r.flint@erasmusmc.nl

H. Rob Taal

h.taal@erasmusmc.nl

1 Department of Pediatrics, Division Neonatology, Erasmus University Medical Center, Rotterdam, Netherlands

2 Department of Development and Regeneration and Department of Pharmaceutical and Pharmacological Sciences, KU Leuven, Leuven, Belgium

3 Department of Pharmacy, Erasmus University Medical Center, Rotterdam, Netherlands

\section{Repurposing of drugs}

Using "old" drugs for new indications is called repurposing. The development of new drugs (drug discovery) takes a lot of time and resources [2], which makes drug repurposing attractive as an efficient way for "new therapies." Drug repurposing allows for shorter routes to the clinic and substantially lower costs [3]. A well-known example of drug repurposing is sildenafil; sildenafil was repurposed from a hypertension drug to a drug for erectile dysfunction, and subsequently for pulmonary hypertension, also in neonates. Other illustrations specific to the field of neonatal pharmacotherapy are indomethacin, ibuprofen, and paracetamol (pain and fever to patent ductus arteriosus), propranolol ( $\beta$-blocker to hemangioma), or Insulin Growth Factor-1 (Laron dwarfism to retinopathy of prematurity or bronchopulmonary dysplasia) [4].

Along this concept, PTX was registered to treat intermittent claudication and mainly used in the geriatric population when Lauterbach et al. administered PTX off-label for the first time in neonatal sepsis in 1994 [5]. From in vitro animal and adult studies, it was observed that PTX could reduce tumor necrosis factor alfa (TNF-a), and thereby could attenuate the hyper inflammatory reaction. Lauterbach et al. hypothesized that inhibiting TNF-a could enhance survival and administered PTX to 16 septic neonates [6]. Since then, there has been a growing interest in PTX for this particular indication [1].

Repurposing is a great opportunity, but still necessitates product development for neonates. First, pharmaceutical formulations for adults may need additional manipulations for use in neonates. Second, formulations often contain excipients that might be harmful or toxic to neonates, such as benzyl alcohol and propylene glycol [7]. For example, the commercially available preparation of doxapram (Dopram $®$ ) in the USA is contraindicated for use in neonates as it contains benzyl alcohol, which might be harmful to infants, while a benzyl alcohol-free formulation in Europe enables a wider use to treat 
apnea of prematurity [8]. Third, data on compatibility of repurposed drugs are needed. Due to the limited intravenous accesses/catheters, simultaneous co-administration of drugs in neonates is common. Incompatibility between drugs or excipients may lead to lost efficacy of drugs or a physiochemical precipitate that may damage blood vessels. Finally and most relevant, a neonatal dosage cannot simply be extrapolated from the adult dosage in the label, even more if the drug is used for another indication. Unfortunately, for most drugs used in neonates, the optimal dosage has not yet been investigated in phase II dose-seeking studies [9-11], as we commonly immediately jump to phase III research on efficacy in neonates using a single dosage in the absence of prior dosefinding study information. In the subsequent placebo controlled trial, a sub-optimal dosage may be compared, leading to sub-optimal findings or increased risk of adverse events. Currently, this may also be the case for PTX. Several small studies reported their attempt to assess the efficacy of PTX in neonatal sepsis, and one study is ongoing; however, exposureeffect responses are not yet studied.

\section{Rationale of PTX therapy}

In preterm neonates, an excessive inflammatory response to infection can occur, characterized by high levels of proinflammatory chemical biomarkers and associated with multi-organ failure and mortality $[12,13]$. Hence, it is thought that anti-inflammatory agents, administered together with antibiotics, may reduce mortality and morbidity in neonatal sepsis.

In vitro and vivo studies documented that PTX has antiinflammatory effects: Toll-like receptor-mediated proinflammatory cytokine production is inhibited [14] and production of pro-inflammatory cytokines by phagocytes is reduced [15]. Additionally PTX improves microcirculation [16], which is a key element in sepsis, and PTX may improve hemodynamics in sepsis [17]. In 1996, Lauterbach et al. showed that PTX modulates the excessive inflammatory response in preterm neonates, which was characterized by a reduction of the pro-inflammatory cytokine TNF-a, when PTX was administered to preterm neonates with sepsis [5]. Also, during sepsis, the distribution of the antibiotics to the infection site might be reduced by impaired microcirculation. Considering that PTX improves microcirculation, it might facilitate distribution of antibiotics which may improve the efficacy of antibiotic therapy.

PTX is metabolized to at least seven metabolites of which three are considered to be pharmacologically active: Lisofylline (M1), M4, and M5. M1 and PTX are found in higher concentrations than M4 and M5 [18] and inhibit TNF-a release more potently [19]. In adults, it is known that hepatic impairment can influence the levels of PTX and its metabolites [20]; hence, maturational changes are thought to influence the exposure in preterm neonates. Recently, Salman et al. reported a first population pharmacokinetic model of PTX and its metabolites in a small cohort of 26 preterm infants receiving one weight-based dosage, describing that clearance of PTX increased with postmenstrual age [21].

\section{PTX exposure-effect relation in preterm neonates: data are needed}

In adult patients, there is limited clinical benefit of PTX therapy during sepsis. Moreover, in vitro, it has been observed that the effect of PTX during hyper inflammation is less pronounced in adult immune cells than in neonatal cells [22]. This highlights that neonates are not just small adults but a vulnerable population with unique physiological characteristics in whom we also should be aware of rapid maturational changes in physiology [23], which may lead to altered responses to drugs.

It also emphasizes the importance of drug research in neonates. Drugs developed and tested in adults and their subsequent dosages cannot just be extrapolated to neonates. Very few dosing regimens used in neonates are based on research within this specific population. Consequently, this population of therapeutic orphans may receive sub-optimal treatment [9-11]. Not giving the optimal dose is problematic: underdosing may result in inferior efficacy, over-dosing in adverse drug reactions [24]. This may also be the case for PTX. In 1992, Lauterbach et al. [25] for the first time gave PTX to a preterm neonate with a dose of $5 \mathrm{mg} / \mathrm{kg} / \mathrm{h}$ during $6 \mathrm{~h}$ every $24 \mathrm{~h}$ for 3 days. However, this dosage was eminence-driven, and not based on high-quality dose-finding research in preterm neonates. Thus, it is of great importance that the right dosage for PTX is studied. Particularly in preterm neonatal sepsis, lives could be saved by using the optimal dosage regimen. Currently, we are conducting a dose optimization study (phase II, exposure/response study) for PTX in preterm neonatal sepsis (Clinical Trials NCT04152980).

\section{Current experience with PTX: is patient selection and timing of PTX initiation relevant?}

In this journal, Schüller et al. report their experience with PTX in a retrospective cohort of 198 preterm neonates with either severe sepsis or NEC. They used the dose $5 \mathrm{mg} / \mathrm{kg} / \mathrm{h}$ for $6 \mathrm{~h}$ daily $(30 \mathrm{mg} / \mathrm{kg} /$ day), which is the dose that was used by Lauterbach et al. and in other smaller studies [26]. As was discussed earlier, compatibility might be a problem when repurposing drugs. The results of Schüller et al. give insight into the compatibility of PTX, and it is suggested that PTX is compatible with other drugs commonly administered in neonates. There were no serious side effects due to PTX. Their findings suggest that PTX therapy is safe and well tolerated in preterm neonates. Along the same research line, the 
PROTECT trial is recruiting 1800 preterm neonates to investigate PTX efficacy and safety (ACTRN12616000405415). This will hopefully provide more conclusive results on the efficacy of PTX in neonatal sepsis. However, there are potential drawbacks. Firstly, the dosage used $(5 \mathrm{mg} / \mathrm{kg} / \mathrm{h}$ for $12 \mathrm{~h}$, $60 \mathrm{mg} / \mathrm{kg} /$ day for 2 up to 6 days) is neither thoroughly evaluated with priori dose-finding data. Consequently, a suboptimal dosage may be studied. Secondly, any suspected patient will receive either placebo or PTX, while only $50 \%$ of the included patients are expected to have a proven sepsis (or NEC) within $48 \mathrm{~h}$. This could result in overtreatment or signal dilution and could be avoided by introducing objective biomarkers (improve patient selection) that reflect disease severity and are associated with the subsequent clinical course. It is reasonable to assume that PTX patients with (severe) sepsis are most likely to benefit.

Besides case selection, timing also matters. In our center, we use PTX since 2018 in preterm neonates with refractory septic shock. In our experience, PTX might not be effective anymore when the sepsis is already progressed to a stage of refractory septic shock. This phenomenon was also observed in a porcine septic model: when PTX was given when septic shock was already established, PTX was not effective anymore and could even have deleterious effects [27]. This emphasizes that the timing of PTX therapy is of great importance; the sooner in the inflammatory cascade PTX is started, the better.

In conclusion, PTX seems to be an effective and safe adjuvant therapy to treat sepsis in preterm neonates as a potential good illustration of repurposing to neonatal needs. Additional research is needed to explore the exposure-response pattern of PTX, as is the case for the majority of drugs used in neonates. Furthermore, there is need for robust biomarkers to support early patient selection and timing of PTX therapy. As PTX in neonatal sepsis is a promising compound, these additional drug repurposing efforts are important to really enable clinicians to give the right drug, in the right dose to the right patient.

Authors' contributions Serifi Kurul wrote the first draft, further adapted and revised by Karel Allegaert, Robert B Flint and H Rob Taal, and all authors approved the final version of the paper.

\section{References}

1. Pammi M, Haque KN (2015) Pentoxifylline for treatment of sepsis and necrotizing enterocolitis in neonates. Cochrane Database Syst Rev 3:CD004205

2. Paul SM, Mytelka DS, Dunwiddie CT, Persinger CC, Munos BH, Lindborg SR, Schacht AL (2010) How to improve R\&D productivity: the pharmaceutical industry's grand challenge. Nat Rev Drug Discov 9:203

3. Ashburn TT, Thor KB (2004) Drug repositioning: identifying and developing new uses for existing drugs. Nat Rev Drug Discov 3: 673
4. Allegaert K, Smits A, Simons S, Van den Anker J (2018) Perspectives in neonatal pharmacology: drug discovery, knowledge integration and structured prioritization. Curr Pharm Des 24:4839 4841

5. Lauterbach R, Zembala M (1996) Pentoxifylline reduces plasma tumour necrosis factor-alpha concentration in premature infants with sepsis. Eur J Pediatr 155:404-409

6. Lauterbach R, Pawlik D, Tomaszczyk B, Cholewa B (1994) Pentoxifylline treatment of sepsis of premature infants: preliminary clinical observations. Eur J Pediatr 153:672-674

7. Nellis G, Metsvaht T, Varendi H, Toompere K, Lass J, Mesek I, Nunn AJ, Turner MA, Lutsar I, consortium E (2015) Potentially harmful excipients in neonatal medicines: a pan-European observational study. Arch Dis Child 100:694-699

8. Flint RB, Weteringen WV, Voller S, Poppe JA, Koch BCP, de Groot R, Tibboel D, Knibbe CAJ, Reiss IKM, Simons SHP, Dino Research G (2017) Big data analyses for continuous evaluation of pharmacotherapy: a proof of principle with Doxapram in preterm infants. Curr Pharm Des 23:5919-5927

9. Schrier L, Hadjipanayis A, Stiris T, Ross-Russell RI, Valiulis A, Turner MA, Zhao W, De Cock P, de Wildt SN, Allegaert K (2020) Off-label use of medicines in neonates, infants, children, and adolescents: a joint policy statement by the European Academy of Paediatrics and the European Society for Developmental Perinatal and Pediatric Pharmacology. Eur J Pediatr. https://doi.org/10.1007/s00431-019-03556-9

10. Turner MA (2011) Neonatal drug development. Early Hum Dev 87: 763-768

11. Turner MA, Lewis S, Hawcutt DB, Field D (2009) Prioritising neonatal medicines research: UK Medicines for Children Research Network scoping survey. BMC Pediatr 9:50

12. Strunk T, Inder T, Wang X, Burgner D, Mallard C, Levy O (2014) Infection-induced inflammation and cerebral injury in preterm infants. Lancet Infect Dis 14:751-762

13. Wynn J, Cornell TT, Wong HR, Shanley TP, Wheeler DS (2010) The host response to sepsis and developmental impact. Pediatrics 125:1031-1041

14. Heller S, Weber K, Heller A, Urbaschek R, Koch T (1999) Pentoxifylline improves bacterial clearance during hemorrhage and endotoxemia. Crit Care Med 27:756-763

15. Neuner P, Klosner G, Schauer E, Pourmojib M, Macheiner W, Grünwald C, Knobler R, Schwarz A, Luger TA, Schwarz T (1994) Pentoxifylline in vivo down-regulates the release of IL-1 beta, IL-6, IL-8 and tumour necrosis factor-alpha by human peripheral blood mononuclear cells. Immunology 83:262

16. Schröer RH (1985) Antithrombotic potential of pentoxifylline a hemorheologically active drug. Angiology 36:387-398

17. Yang S, Zhou M, Koo DJ, Chaudry IH, Wang P (1999) Pentoxifylline prevents the transition from the hyperdynamic to hypodynamic response during sepsis. Am J Phys 277:H1036H1044

18. Smith RV, Waller ES, Doluisio JT, Bauza MT, Puri SK, Ho I, Lassman HB (1986) Pharmacokinetics of orally administered pentoxifylline in humans. J Pharm Sci 75:47-52

19. Fantin M, Quintieri L, Kusz E, Kis E, Glavinas H, Floreani M, Padrini R, Duda E, Vizler C (2006) Pentoxifylline and its major oxidative metabolites exhibit different pharmacological properties. Eur J Pharmacol 535:301-309

20. Frampton JE, Brogden RN (1995) Pentoxifylline (Oxpentifylline). Drugs Aging 7:480-503

21. Salman S, Hibbert J, Page-Sharp M, Manning L, Simmer K, Doherty DA, Patole S, Batty KT, Strunk T (2019) Effects of maturation and size on population pharmacokinetics of pentoxifylline and its metabolites in very preterm infants with suspected late-onset sepsis or necrotizing enterocolitis: a pilot study incorporating clinical outcomes. Br J Clin Pharmacol 85:147-159 
22. Schüller SS, Wisgrill L, Herndl E, Spittler A, Förster-Waldl E, Sadeghi K, Kramer BW, Berger A (2017) Pentoxifylline modulates LPS-induced hyperinflammation in monocytes of preterm infants in vitro. Pediatr Res 82:215

23. de Wildt SN (2011) Profound changes in drug metabolism enzymes and possible effects on drug therapy in neonates and children. Expert Opin Drug Metab Toxicol 7:935-948

24. Ku LC, Smith PB (2015) Dosing in neonates: special considerations in physiology and trial design. Pediatr Res 77:2

25. Lauterbach R (1993) Pentoxifylline treatment of persistent pulmonary hypertension of newborn. Eur J Pediatr 152:460-460
26. Pammi M, Weisman LE (2015) Late-onset sepsis in preterm infants: update on strategies for therapy and prevention. Expert Rev AntiInfect Ther 13:487-504

27. Ridings PC, Windsor ACJ, Sugerman HJ, Kennedy E, Sholley MM, Blocher CR, Fisher BJ (1994) Beneficial cardiopulmonary effects of pentoxifylline in experimental sepsis are lost once septic shock is established. Arch Surg 129:1144-1152

Publisher's note Springer Nature remains neutral with regard to jurisdictional claims in published maps and institutional affiliations. 